\title{
MIDAS
}

Museus e estudos interdisciplinares

$11 \mid 2020$

Dossier temático: "Perspetivas sobre o museu eclético"

\section{Gostos ecléticos em coleções, repercussões em museus nacionais: o caso da coleção Ferreira das Neves}

Eclectic tastes in collections, repercussions in national museums: the case of the collection Ferreira das Neves

\section{Marize Malta}

\section{OpenEdition}

\section{Journals}

\section{Edição electrónica}

URL: http://journals.openedition.org/midas/2067

DOI: $10.4000 /$ midas. 2067

ISSN: 2182-9543

\section{Editora:}

Alice Semedo, Paulo Simões Rodrigues, Pedro Casaleiro, Raquel Henriques da Silva, Ana Carvalho

\section{Refêrencia eletrónica}

Marize Malta, «Gostos ecléticos em coleções, repercussões em museus nacionais: o caso da coleção Ferreira das Neves », MIDAS [Online], 11 | 2020, posto online no dia 19 novembro 2020, consultado no dia 21 novembro 2020. URL : http://journals.openedition.org/midas/2067 ; DOI : https://doi.org/ $10.4000 /$ midas. 2067

Este documento foi criado de forma automática no dia 21 novembro 2020

\section{c) (i) (2)}

Midas is licensed under a Creative Commons Attribution-NonCommercial-ShareAlike 3.0 International License 


\section{Gostos ecléticos em coleções,} repercussões em museus nacionais: o caso da coleção Ferreira das Neves

Eclectic tastes in collections, repercussions in national museums: the case of the collection Ferreira das Neves

\section{Marize Malta}

\section{NOTA DO EDITOR}

Artigo recebido a 12.02.2019

Aprovado para publicação a 15.03.2020

\section{Notas introdutórias sobre o colecionismo privado no séc. XIX}

1 Praticamente todos os museus nacionais criados no século XIX contaram com antigas coleções de particulares para constituírem os seus acervos, estando assim interligados às práticas de colecionismo privado e aos seminais gabinetes de curiosidades. Como lembra Luis Diaz Viana, professor e investigador do Centro de Ciências Humanas e Sociais de Madrid:

Os museus são um dos melhores exemplos de como as culturas dominantes reproduzem e representam a si mesmas, desdenhando de tudo que não esteja em conformidade com a sua ordem canônica, condenando a ausência daquelas manifestações culturais que não têm lugar neles. (Viana 2008, 15)

2 Muitos acervos oitocentistas, e até um pouco posteriores, beneficiaram-se de doações e das dispersões de coleções, coleções não só com objetos excecionais, mas igualmente compostas de objetos do quotidiano, potencialmente artefactos com memórias históricas, testemunhas do engenho artístico do homem, sintomas do desejo de adquirir 
objetos representativos de culturas, estilos e naturezas diversas (Pellegrini 2018), coleções que adquiriam uma íntima coerência na decoração das casas dos colecionadores e que tomaram outros vieses ao se adentrarem pelos museus (Malta 2012).

3 Se a prática do colecionismo e o acesso visual às obras de arte remontam há séculos, a democratização das práticas de olhar e colecionar tomou dimensões sem precedentes no século XIX, ainda mais no Brasil, cuja prática colecionista só se tornou significativa na segunda metade do século XIX (Knauss 2001). Tal fenómeno também ocorreu em simultâneo em países como Portugal (Silva 2003), Espanha (Socias e Gkozgkou 2013), Itália (Pellegrini 2018) e, nas Américas, nomeadamente nos Estados Unidos (Dilworth 2003) e na Argentina (Baldasarre 2006). Nesse contexto desenvolveu-se um amplo consumo de objetos artísticos e cópias com predomínio de peças europeias, revalorizando inicialmente a arte medieval, a arte cristã e o orientalismo gótico e, em seguida, nos finais do XIX, os primitivos, a antiguidade, o rococó e os contemporâneos (León 2010, 41). A este consumo somaram-se objetos de interesse científico, antropológico e arqueológico, cujas presenças e ausências demarcam tanto oportunidades de mercado e de sociabilidades, quanto preferências pessoais e identificadores de estatuto cultural.

\section{O Museu Nacional, o Museu Histórico Nacional e o Museu Nacional de Belas Artes}

4 No Brasil, três foram os museus que, tomando a denominação de nacional, assumiram a missão do que deveria ser preservado em cada uma das suas modalidades como representantes da memória material do país - o Museu Nacional, o Museu Histórico Nacional e o Museu Nacional de Belas Artes. Por outro lado, fruto de situações singulares e ao mesmo tempo comum na história dos museus oitocentistas, os seus acervos não se constituíram somente de peças brasileiras, ou exclusivas de cada modalidade do conhecimento, mas acolheram objetos de variadas culturas, geografias e simbologias. Podemos considerá-los museus ecléticos, em que «a nação demandava sua visibilidade» (Guimarães 2006, 10) e «o passado parecia controlar definitivamente a vida do presente» (Guimarães 2006, 8), um passado que reunia muitos antepassados, procurando construir o que Paul Ricoeur denominou de "justa memória" (2000).

o Museu Nacional (Universidade Federal do Rio de Janeiro), lamentavelmente incendiado em 2 de setembro de 2018, foi criado por D. João VI como Museu Real, em 6 de junho de 1818. Era a instituição científica mais antiga do Brasil e reunia, até há pouco tempo, uma enorme diversidade de material relativo à antropologia biológica, à arqueologia, à etnologia, à geologia, à paleontologia e à zoologia. $\mathrm{O}$ acervo nuclear foi fruto de transferências das coleções existentes na Casa dos Pássaros (fundada em 1784); da coleção Werner de mineralogia (comprada pelo conde da Barca para a Coroa portuguesa); de instrumentos, máquinas e gabinetes que se encontravam em outras instituições; e de artefactos etnográficos provenientes de variadas regiões do Brasil. Contou também com a doação da família real de objetos de arte e antiguidade. Tinha como intenção divulgar entre os brasileiros os conhecimentos e investigações das ciências naturais, bem como estudar os produtos naturais do país (Lopes 1997, 44), um típico museu de história natural de caráter universal. 
O museu, localizado inicialmente no Campo de Santana, após a proclamação da República transferiu-se para o Paço de São Cristóvão (fig. 1), antes residência oficial da família imperial que foi banida do país, como um ato deliberado de apagamento de memória da monarquia no Brasil. Sem ser um espaço destinado a abrigar um acervo de história natural, muitas adaptações foram realizadas. Ossadas de animais pré-históricos poderiam ocupar a antiga sala de baile, artefactos pré-colombianos espalhavam-se no gabinete do imperador, peças indígenas conviviam com a decoração destinada antes à sala dos embaixadores. Uma ou outra peça pertencente à antiga moradia palaciana acabou sendo incorporada no acervo por ter sido esquecida após o famigerado Leilão do Paço, que pôs tudo à venda (Santos 1940).

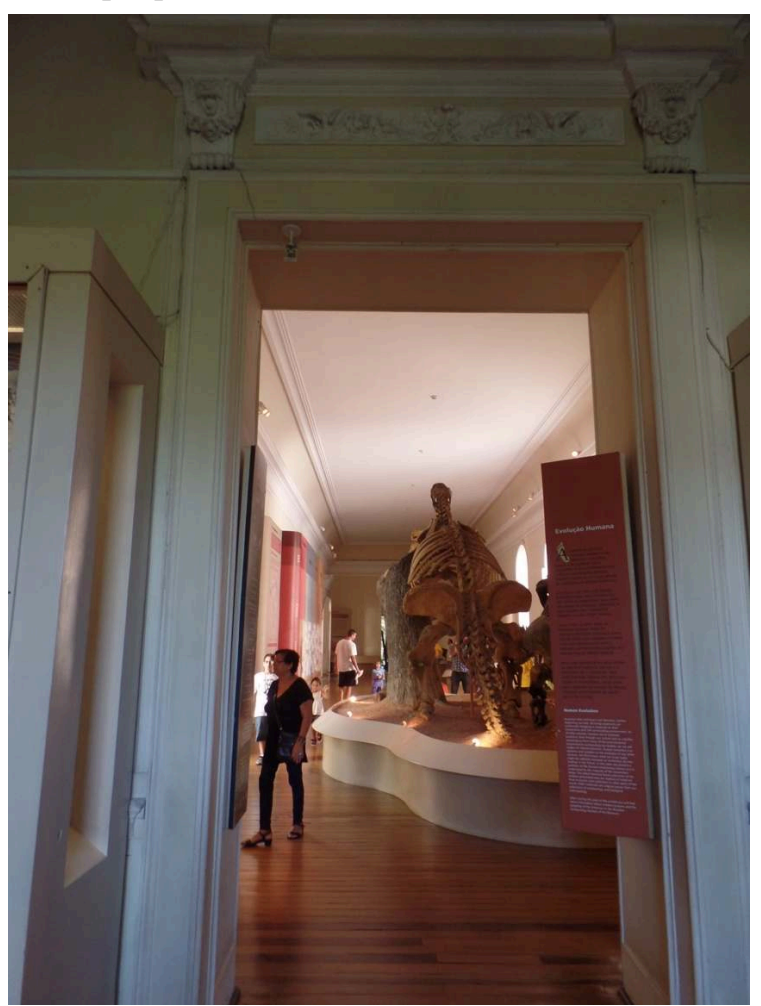

Fig. 1 - Salão com ossadas de animais pré-históricos. Museu Nacional - Universidade Federal do Rio de Janeiro (UFRJ), antigo Paço de São Cristóvão, 2015

Fotografia da autora

7 A "caixa" que envolvia a coleção, ou seja, o edifício, era por si só um tesouro e é importante salientar que, como o Museu Nacional, inúmeros museus adaptaram as suas demandas expositivas a antigas moradias aristocráticas, sendo poucos os casos de novas construções oitocentistas projetadas especialmente para museus, o que acabou por constituir uma prática. Decorações típicas de nobres residências serviram de fundo para a apresentação dos acervos, ocasionando uma convivência que pouco tem sido avaliada pelos historiadores da arte e da museologia. Desse modo, muitas "caixas de tesouros" enquanto antigos palácios reforçavam a ideia de que os tesouros da memória eram próprios de construções grandiosas e com decorações esplendorosas. Assim, o maior acervo museológico do Brasil, no final do século XIX, alojou-se no maior palácio do país, oferecendo duas oportunidades: entrar nos espaços reais e poder experienciar a decoração antes restrita a alguns privilegiados e ter acesso às peças que procuravam contar no Brasil a história do mundo por meio da sua materialidade. Ali, o mundo apresentava-se através da sua diversidade natural e humana, colocando o Brasil com as 
suas peças etnográficas e biológicas, e também por intermédio de um palácio imperial, em confronto com antigas civilizações, aos demais biossistemas do mundo e das tradições monárquicas europeias. Como num atlas, o Brasil inseria-se no mapa das geografias museológicas, confirmando a sua predisposição de assumir um destino protagonista no processo civilizador em que civilidade e progresso eram interdependentes. Nenhuma nação que pretendesse figurar no atlas da civilização podia prescindir de museus, de grandes museus com decorações palacianas, palácio que, como museu, passava a ser moradia do conhecimento e do público.

Se tomarmos como exemplo um dos primeiros museus europeus projetados especialmente para esse fim, o Museu de História da Arte de Viena, criação de Gottfried Semper e Karl von Hasenauer, de 1891, a decoração interior de ordem historicista funcionava como ambientação temática das peças, permitindo perceber o quanto a decoração era importante suporte museológico. Além disso, o estilo renascentista italiano impresso na arquitetura falante, típica do século XIX, remetia para o tempo do surgimento dos gabinetes de curiosidades, fazendo corresponder simbolicamente os museus a gigantescos gabinetes de maravilhas. Ainda diante da incorporação de coleções centenárias, o Museu de História da Arte de Viena, como tantos outros museus oitocentistas, acolheu a diversidade de peças que constituíam as coleções particulares, sublinhando alguns aspetos da tradição do colecionismo: o interesse, o gosto e as oportunidades de cada colecionador, a forma de apresentar a coleção (em ambientes e em forma de catálogos), a potência didática das peças e a sua relação com o conhecimento e o poder. Desse modo, os museus oitocentistas e os seus projetos de representação da nação empreenderam através dos seus acervos primordiais uma grande síntese dos gostos pessoais aristocráticos que, com a sua abertura ao público, compartilhavam a arte como uma coleção coletiva capaz de representar uma pretensa história de todos.

9 Regressando ao caso dos museus nacionais no Brasil, o Museu Histórico Nacional valeuse de outras contingências para alojar o seu acervo. Fundado em 2 de agosto de 1922, constava inicialmente de duas galerias no Palácio das Grandes Indústrias na Exposição Internacional Comemorativa, à data do centenário da independência, construção onde depois se alojou, assim como o Petit e o Grand Palais, em Paris, que se constituíram em espaços museológicos/expositivos aproveitando as construções dos pavilhões das exposições universais, para citar apenas um exemplo. As salas pioneiras denominavamse «Da Colônia à Monarquia» e «Da Monarquia à República», pontuando a história da nação a partir de dois períodos políticos e por meio da justaposição de pinturas, retratos, esculturas e objetos, densamente reunidos (fig. 2). Da posse material de colecionadores, passava-se à posse visual do público. Num golpe de olhar, vislumbravam-se séculos de história, certamente uma versão escolhida por Gustavo Barroso (1888-1959), o primeiro e longevo diretor, «ignorando a pluralidade da sociedade e a contribuição de negros e índios, os 'outros' internos da nação» (Magalhães 2006, 38). Junto a armas e estandartes, provenientes de acervos militares, foram sendo incorporados móveis, louça, prataria, objetos de devoção e de uso quotidiano, moedas e medalhas (estes últimos provenientes da coleção de D. João VI) (Santos 2006, 35). 


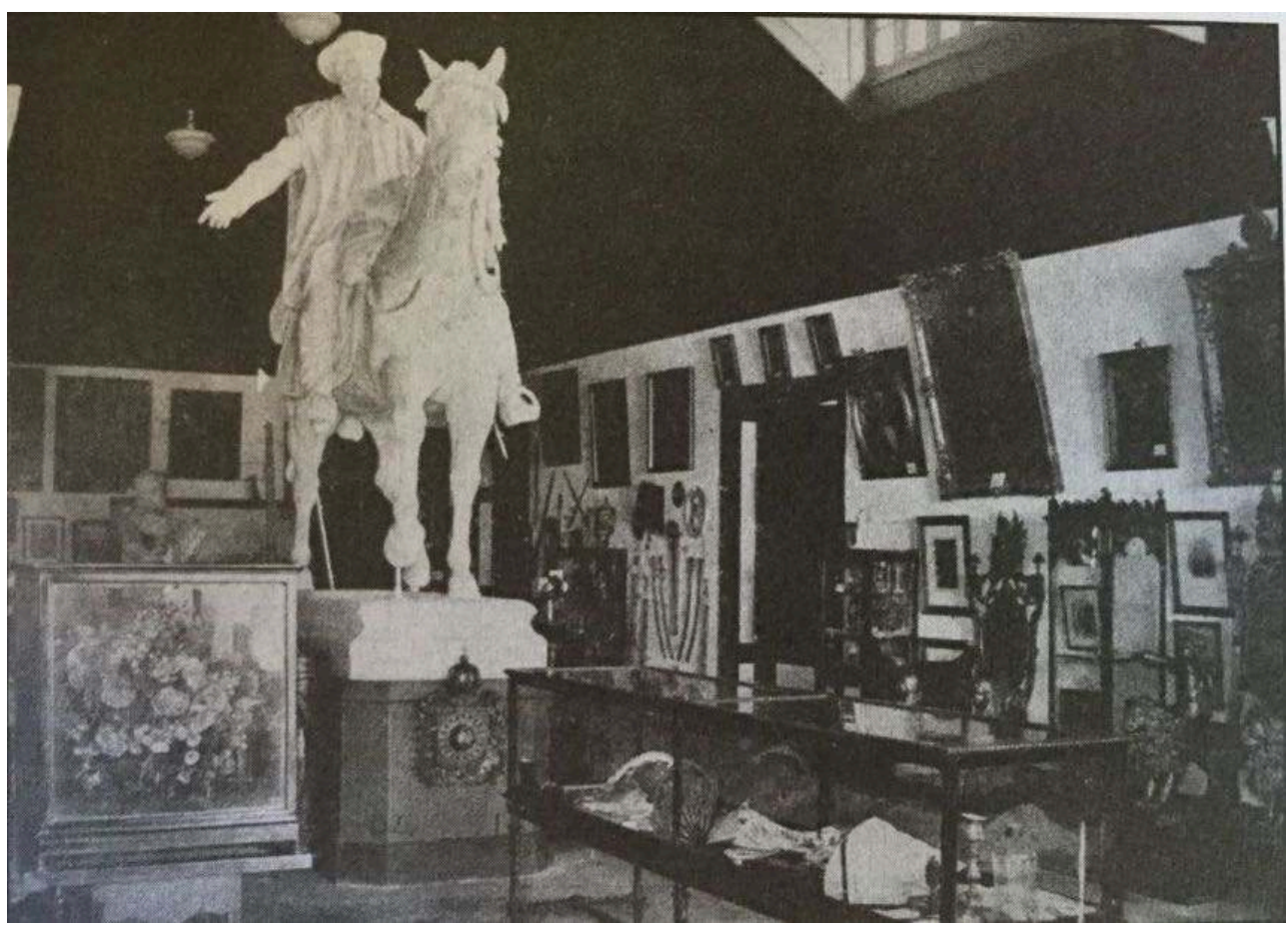

Fig. 2 - Sala «Da Colônia à Monarquia» do seminal Museu Histórico Nacional no Palácio das Grandes Indústrias na Exposição Internacional Comemorativa, 1922

Arquivo do Museu Histórico Nacional

Criado pelo presidente Epitácio Pessoa (1865-1942) para dar conta da história da nação, o acervo do Museu Histórico Nacional conta hoje com mais de 170 mil objetos, envolvendo numismática, artefactos da pré-história aos dias atuais, com pinturas, esculturas, joalharia, cestaria, indumentária, brinquedos, armaria, objetos de arte, mobiliário, têxteis e artefactos banais. Mantém, desse modo, a tradição do ecletismo no seu acervo, que contou com campanhas de doação de particulares e institucionais, como a Biblioteca Nacional e o Arquivo Nacional.

O senador Miguel Calmon du Pin e Almeida (1879-1935) (Abreu 1996), a família Guinle (Knauss e Alves 2015), a viscondessa de Cavalcanti (1852-1946) (Christo 2016) estão entre os principais particulares que contribuíram para a constituição do acervo seminal. Os três casos são exemplos emblemáticos de coleções ecléticas. A viscondessa de Cavalcanti, por exemplo, não se restringiu ao Museu Histórico Nacional, empreendendo doações ao Instituto Histórico e Geográfico Brasileiro, à Escola Nacional de Belas Artes, ao Museu Nacional e ao Museu Mariano Procópio (Christo 2016), escolhendo peças que melhor se adequariam a cada instituição conforme o seu perfil, dispersando o conjunto e debilitando seu ecletismo original.

Vale a pena lembrar que, antes da constituição do Museu Histórico Nacional, o Instituto Histórico e Geográfico Brasileiro, fundado em 1838, havia constituído em 1851 um museu para aonde eram destinadas muitas doações. Instalava-se numa das salas do Paço Imperial e somente no início do século XX angariou sede própria. Portanto, antes de um museu que se intitulava histórico nacional, foi o Instituto que assumia a missão «de recolher e organizar os materiais referentes à história e geografia brasileiras» (IHGB 2018, s/p), para onde confluíam as doações dos colecionadores. Móveis, louça brasonada, pinturas, especialmente retratos, perfizeram o acervo, trazendo geografias 
do Oriente, da Europa e do Brasil, evidenciando as relações que constituíram a sua história multicultural contada pelas elites.

O terceiro museu nacional, o Museu Nacional de Belas Artes, fruto do decreto que também instituiu o Serviço de Patrimônio Histórico e Artístico Nacional, em 1937, valeu-se da transferência de mais de 3500 obras que pertenciam à chamada pinacoteca da Escola Nacional de Belas Artes (ENBA) (Malta 2017), nome atualizado após a República da Academia Imperial de Belas Artes, fundada em 1816 por D. João VI. A coleção da pinacoteca da Academia foi primordialmente formada por doação de obras pertencentes a D. João VI e trazidas por Joachim Lebreton da França (1760-1819) (Pereira 2016), na ocasião da vinda da caravana de artistas e artífices franceses que tinham a intenção de criar uma Escola Real de Ciências Artes e Ofícios (Telles 2017). Este núcleo foi acrescido com obras provenientes do envio de pensionistas, de prémios de exposições gerais, de provas de concursos, mas igualmente com compras e doações, estas últimas mais relevantes, visto a Academia reclamar da falta de verbas para aquisição de obras.

Antes do seu falecimento em 1921, o colecionador Salvador de Mendonça (1841-1913), por exemplo, contribuiu com doações à Escola Nacional de Belas Artes. Em 1922, a viúva do Barão de São Joaquim cumpriu o desejo do falecido marido, doando 64 obras à pinacoteca da Escola, na maioria, pinturas a óleo, além de desenhos e aguarelas europeias. Também o conde de Figueiredo (1843-1917) doou 38 pinturas (Knauss 2001). É importante salientar que apesar de as doações terem sido realizadas no século XX, foram todas constituídas nas últimas décadas do século XIX. Decerto, com um museu tão específico - de obras de arte - canalizava-se para o acervo um certo tipo de objeto o de arte, como desenhos, pinturas e esculturas, mas não somente do Brasil. Há um significativo acervo de arte estrangeira, seja por meio de originais ou por intermédio de cópias, representando as principais escolas artísticas que, antes de tudo, tinham o intuito didático de instruir os futuros artistas que estudavam na Academia/Escola (fig. 3). 


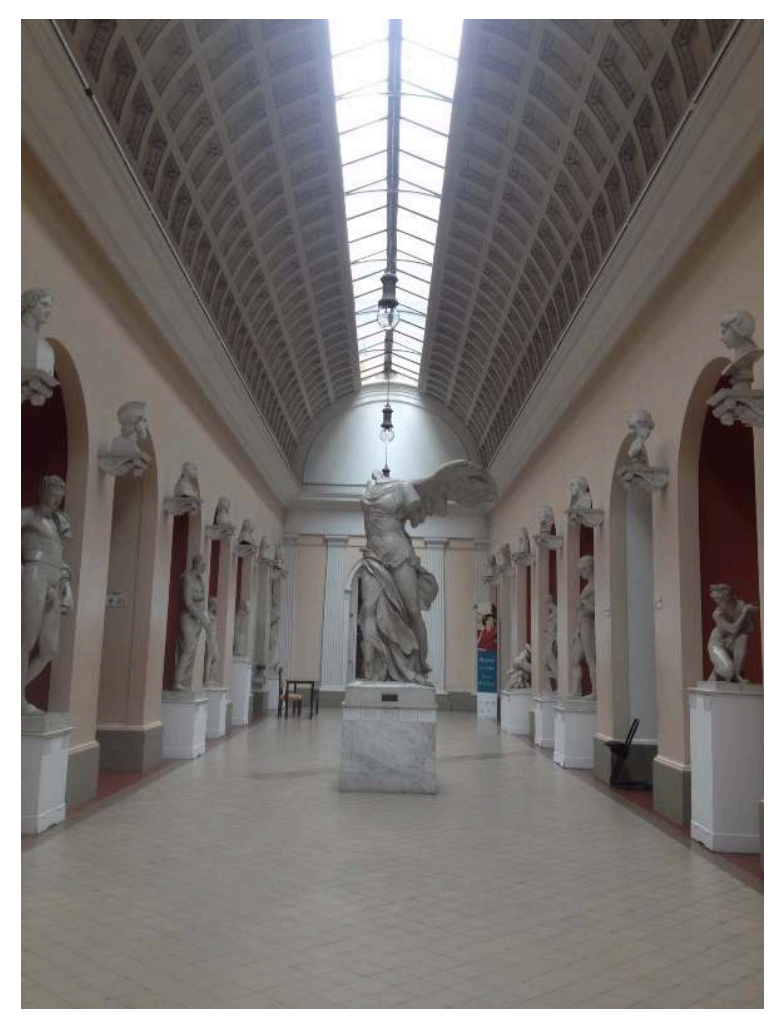

Fig. 3 - Galeria das Moldagens da antiga Escola Nacional de Belas Artes, Museu Nacional de Belas Artes, 2017

Fotografia da autora

Ciência, história e arte, assim se deu a sequência da importância dada ao tipo de conhecimento que justificava a criação dos museus nacionais no Brasil, mesmo que nos seus acervos todas as três categorias pudessem estar presentes. De certo, foram o Museu Nacional, o museu do Instituto Histórico e Geográfico Brasileiro e a Pinacoteca da Academia/Escola Nacional de Belas Artes os três acervos que narravam, à sua maneira, uma certa história do Brasil de Oitocentos, ou seja, pelo viés da ciência, da história e da arte. Algumas coleções oitocentistas também assumiam narrativas que propunham a conjugação entre história, ciência e arte, como é o caso da coleção Jerônimo Ferreira das Neves.

\section{A coleção Ferreira das Neves}

16 Jerônimo Ferreira das Neves (1854-1918), nascido no Rio de Janeiro, era filho do comendador Francisco Ferreira das Neves (?-1871), que era original da região de Setúbal (Portugal). Jerônimo Ferreira das Neves viveu, com a sua esposa Eugênia Barbosa de Carvalho Neves (1860-1946), em Lisboa e Paris nas décadas de 1880 e 1890, reunindo uma coleção eclética, composta por livros raros, manuscritos, portulanos, moedas, medalhas, porcelanas, têxteis, relógios, pinturas antigas e modernas, móveis e muitos outros pequenos objetos. Era reconhecido especialmente como bibliófilo (Vasconcelos 1896, 83; Sousa Viterbo 1903, 147), sendo que a sua vertente de colecionador de arte não é mencionada pelos seus contemporâneos, com exceção de alguns relógios citados por Sousa Viterbo $(1915,11-12)$, que afirmava que era uma 
pequena coleção de qualidade. No entanto, foi a coleção artística de Ferreira das Neves que foi doada à Escola Nacional de Belas Artes.

Coube a Eugênia Neves praticar a doação, facto que somente ocorreu em 1947, após o seu falecimento no ano anterior. A doação, portanto, foi realizada por Eugênia Neves e coube a ela a escolha das peças a serem doadas. Antes disso, em 1929, Eugênia Neves endereçou uma carta ao diretor do Museu Histórico Nacional, ofertando uma matriz de gravura em metal, realizada por Gaspar Froius Maxadus 1759-1796), que representava o príncipe regente D. João VI e Carlota Joaquina apresentando o seu filho à Nação e à História, infante este que seria o futuro imperador do Brasil, D. Pedro I. A seu ver, esta seria a peça da coleção que detinha incontestável interesse histórico e, por isso, digna de figurar no acervo que se propunha contar a história da nação.

No testamento de Eugênia Neves, redigido em 1934, os livros raros do marido seriam encaminhados para a Academia Brasileira de Letras e os objetos artísticos para a Escola Nacional de Belas Artes. Para a primeira instituição, foram destinados dois relógios, um exemplar de Os Lusíadas e um armário-biblioteca com 364 livros, cujo valor estava avaliado em CR $\$ 292.000,00$. Para a Escola Nacional de Belas Artes, cinco categorias foram discriminadas no testamento, com os seus respetivos valores: móveis e objetos de arte (CR\$ 286.960,00); quadros (CR\$ 181.250,00); joias e pequenos objetos de arte (CR\$ $63.000,00)$; medalhas e moedas (CR\$ 6.875,00); e uma biblioteca com livros "modernos" (CR\$350.000,00).

Vale a pena referir que, com frequência, eram as viúvas dos colecionadores a executarem as doações das coleções às instituições brasileiras, por mais que fossem os nomes dos maridos a intitularem as coleções. Diferente da perspetiva passiva com que a mulher era vista no século XIX, foram elas que protagonizaram os contactos com museus e instituições e a realizarem as doações.

Eugênia Neves no seu testamento colocava condições, nomeadamente que toda a coleção artística permanecesse reunida num único local e que se denominasse coleção Jerônimo Ferreira das Neves, legado de sua viúva. Provavelmente Eugênia Neves não contava com a separação da coleção da Escola Nacional de Belas Artes, arregimentada para o acervo do Museu Nacional de Belas Artes, que aconteceria poucos anos depois da redação de seu testamento. A coleção Ferreira Neves, portanto, era a única coleção não didática que permaneceu na Escola. A coleção Ferreira Neves e todas aquelas que não foram transferidas para o Museu Nacional de Belas Artes, assim como a documentação administrativa desde os tempos da Academia, foram recolhidas e incorporaram o acervo do Museu D. João VI, criado somente em 1979, época em que a Escola já se encontrava integrada na Universidade Federal do Rio de Janeiro, assumindo o nome de Escola de Belas Artes. Como segundo museu da instituição, o seu compromisso detinhase na preservação da memória do ensino artístico no Brasil, salvaguardando obras e documentos.

Quase 60 anos depois da doação de Eugênia Neves, após o Museu D. João VI ter passado por uma renovação museológica na primeira década do século XXI, a coleção passou a estar disponível ao público em toda a sua diversidade e entre obras de ensino académico (figs. 4a e 4b), recuperando a sua natureza eclética e instigando novos questionamentos sobre as coleções oitocentistas, modos de exibição e de compreensão da arte e das suas práticas historiográficas. 
De 1947 até 2009, foram poucas as peças da coleção Ferreira Neves que despertaram interesse de investigação (Teixeira Leite 1960; Serrão 1999; Pereira 2009), concentrando-se o estudo em pinturas e um relevo em faiança. A sua diversidade, apoiada em objetos de artes decorativas, precisou esperar décadas para ser devidamente apreciada e estudada, apontando para um desinteresse historiográfico em uma escola de artes que, mesmo tendo criado um curso de Arte Decorativa em 1948 (Viana 2017), não valorizava a pesquisa de objetos de arte "com utilidade" que estavam ao alcance de professores e estudantes, mais interessados nas artes visuais.

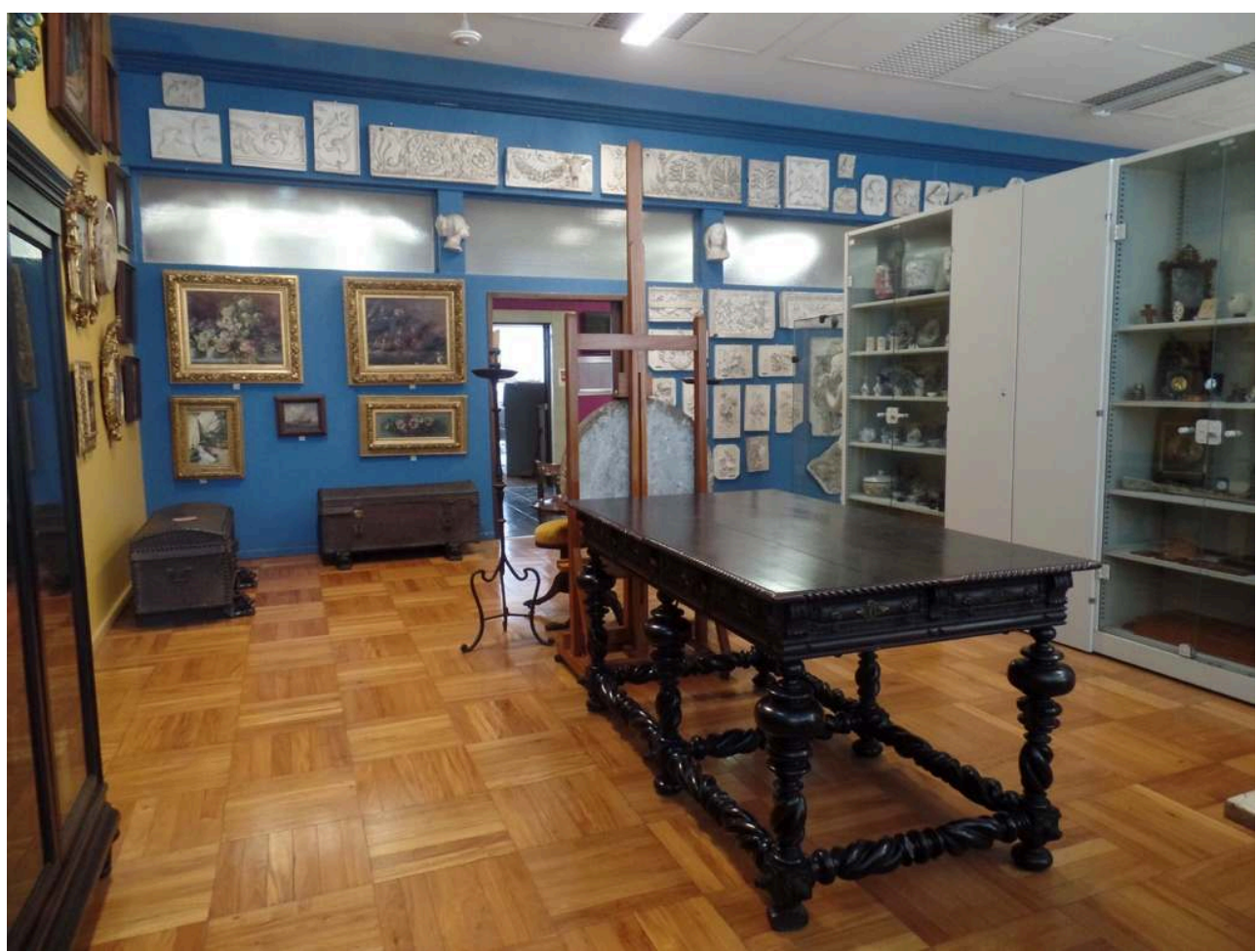

Fig. $4 a$ - Coleção Ferreira das Neves no Museu D. João VI-Escola de Belas Artes-Universidade Federal do Rio de Janeiro, 2016

Fotografia da autora 


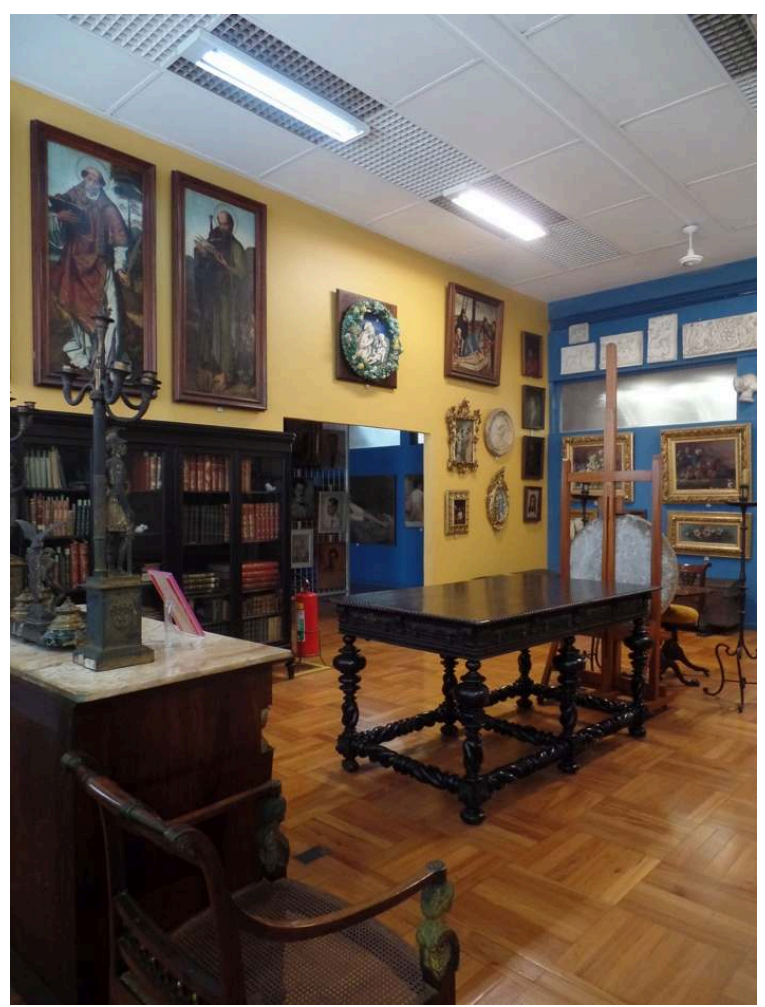

Fig. 4b - Coleção Ferreira das Neves no Museu D. João VI-Escola de Belas Artes-Universidade Federal do Rio de Janeiro, 2016

Fotografia da autora

O casal Ferreira das Neves não reuniu apenas peças antigas de elevado valor estético, especialmente de cunho religioso, mas ainda objetos do quotidiano, de uso comum, perfazendo uma diversidade complexa, reflexo das práticas do colecionismo do período e dos chamados museus ecléticos. Desse modo, os museus alimentavam-se da diversidade das coleções, como as coleções refletiam a diversidade encontrada nos museus, reunindo ciência, história e arte. Importa mencionar que no Brasil, até pelo menos à década de 60 do século $\mathrm{XX}$, era prática montar salas de exposição por colecionador, explicitando a dependência dos acervos às doações de particulares, enquadrando os seus gostos e perpetuando as suas memórias na história do país.

Afora livros e o conjunto de numismática, a coleção conta com apenas um pouco mais que 340 peças, enquadrando-se entre uma "caixa de tesouros" e uma "caixa de surpresas". A “pequena notável”, como costumamos chamá-la (Malta 2016), é composta por um universo múltiplo de peças, basicamente estrangeiras, cujas procedências exatas de todo o conjunto ainda estão sendo investigadas, com itens excecionais e objetos triviais, pinturas quinhentistas e oitocentistas, peças religiosas e de uso quotidiano e banal. Por exemplo, A Descida da Cruz, de Quentin Metsys, os vitrais suíços de batalhas, os baús brasonados em couro lavrado, um crucifixo de marfim e ébano, uma presa de animal, uma espingarda de marfim, um barômetro, um abano com um beija-flor empalhado, um porta-perfume, uma jarra em porcelana chinesa, um escaravelho egípcio em basalto ou uma cómoda em estilo Império, entre outros.

O que se denomina na contemporaneidade de "identidades partilhadas" (Hall 1997) já se configurava em muitas coleções privadas no séc. XIX pelo convívio de peças com procedências e temporalidades diversas, numa espécie de globalização material, 
promovendo nas casas dos seus colecionadores o fenómeno da "compressão espaçotempo" (Hall 1997). O compartilhamento, nesse caso, incidia numa via unilateral, visto que eram objetos os intermediários para se alcançar a compreensão do outro, a qual se acionava pela posse, a posse do outro, mais concernente a uma postura imperialista do que de trocas interculturais simétricas. Contudo, as coleções sobrepuseram-se ao tempo e a certas posturas historiográficas canónicas, permitindo que se volte a elas com outros olhares e posturas que tragam novas luzes à sua diversidade e diferentes proveniências culturais.

Essa variedade de qualidade pode estar relacionada com a ideia disseminada pelos estudos históricos de meados do século XIX que preconizavam encontrar a beleza nos mais variados objetos, enfatizando «a tolerância com toda a forma de arte» (Georgel $2015,282)$ e o interesse por objetos quotidianos antigos que incorporavam na sua materialidade testemunhos de uma memória histórica (Pellegrini 2018). 0 colecionismo burguês oitocentista assumia o desafio da variedade, porém igualmente da repetição (figs. $5 \mathrm{a}, 5 \mathrm{~b}$ e $5 \mathrm{c}$ ). Na coleção Ferreira das Neves há inúmeras porcelanas europeias (22) e especialmente da Companhia das Índias (56), dentre elas muitos pratos (30) e xícaras (19).

O fenómeno da repetição também pode ser encontrado noutras modalidades de objetos na coleção Ferreira das Neves: moedas (287) e medalhas (320), armas (7), relógios (7), leques (6), colchas (4), micro-mosaicos (4), sinetes (7). Mesmo que a quantidade expressiva se deposite nas porcelanas e na numismática/medalhística, é revelador observar a incidência de mini coleções dentro do conjunto maior, apontando o quanto a prática comparativa se fazia presente, só possível quando se reúne uma certa quantidade da mesma tipologia de objetos. É o caso, também significativo, de obras, com variadas materialidades, de cunho religioso (55), desde imagens de santos, cenas com Jesus Cristo ou Nossa Senhora, vestes de bispo a crucifixos, que compreendem as peças com datação mais antiga, acessíveis para aquisição de colecionadores após a extinção das ordens religiosas em Portugal, em 1834, gerando pelas décadas subsequentes uma quantidade expressiva de obras antigas até então enclausuradas em mosteiros e conventos. Nesse caso, a partir de uma temática privilegiada, seria possível debruçar-se sobre como o cristianismo, seja na representação ou no suporte de uso, no culto ou na devoção pessoal, priorizou certas temáticas e linguagens, foi interpretado por artistas de diferentes nacionalidades, períodos e culturas, impregnou a sua iconografia em variados materiais que conjugavam apreciação estética e fé contemplativa. 


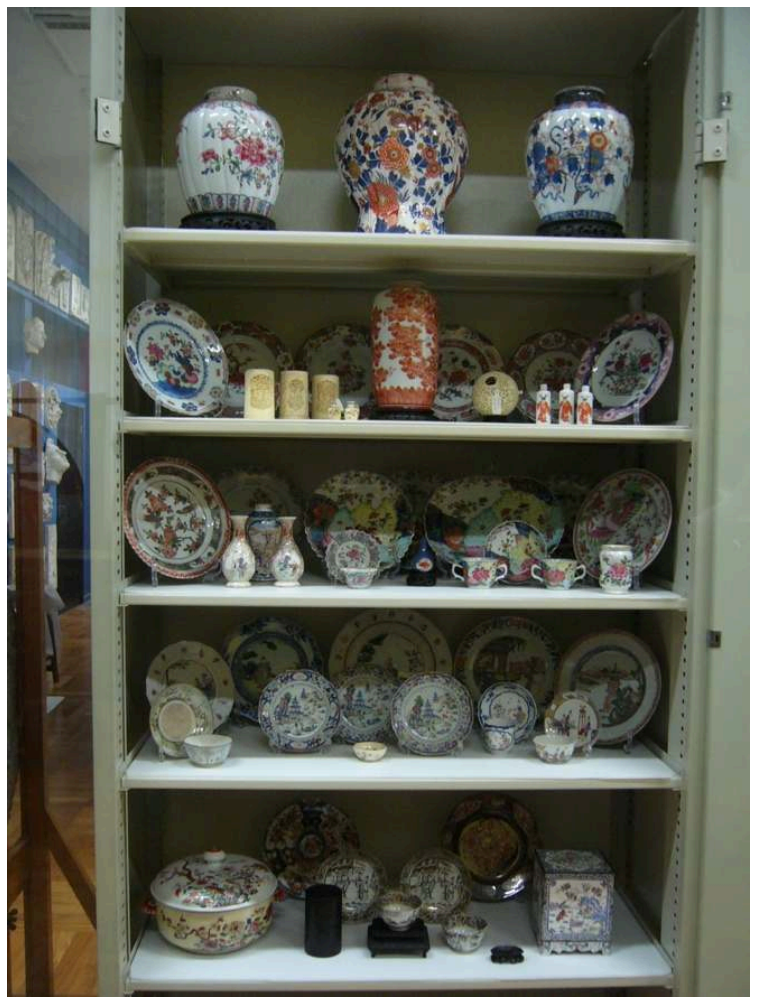

Fig. 5a - Objetos da coleção Ferreira das Neves, Museu D. João VI-Escola de Belas ArtesUniversidade Federal do Rio de Janeiro, 2016

Fotografia da autora

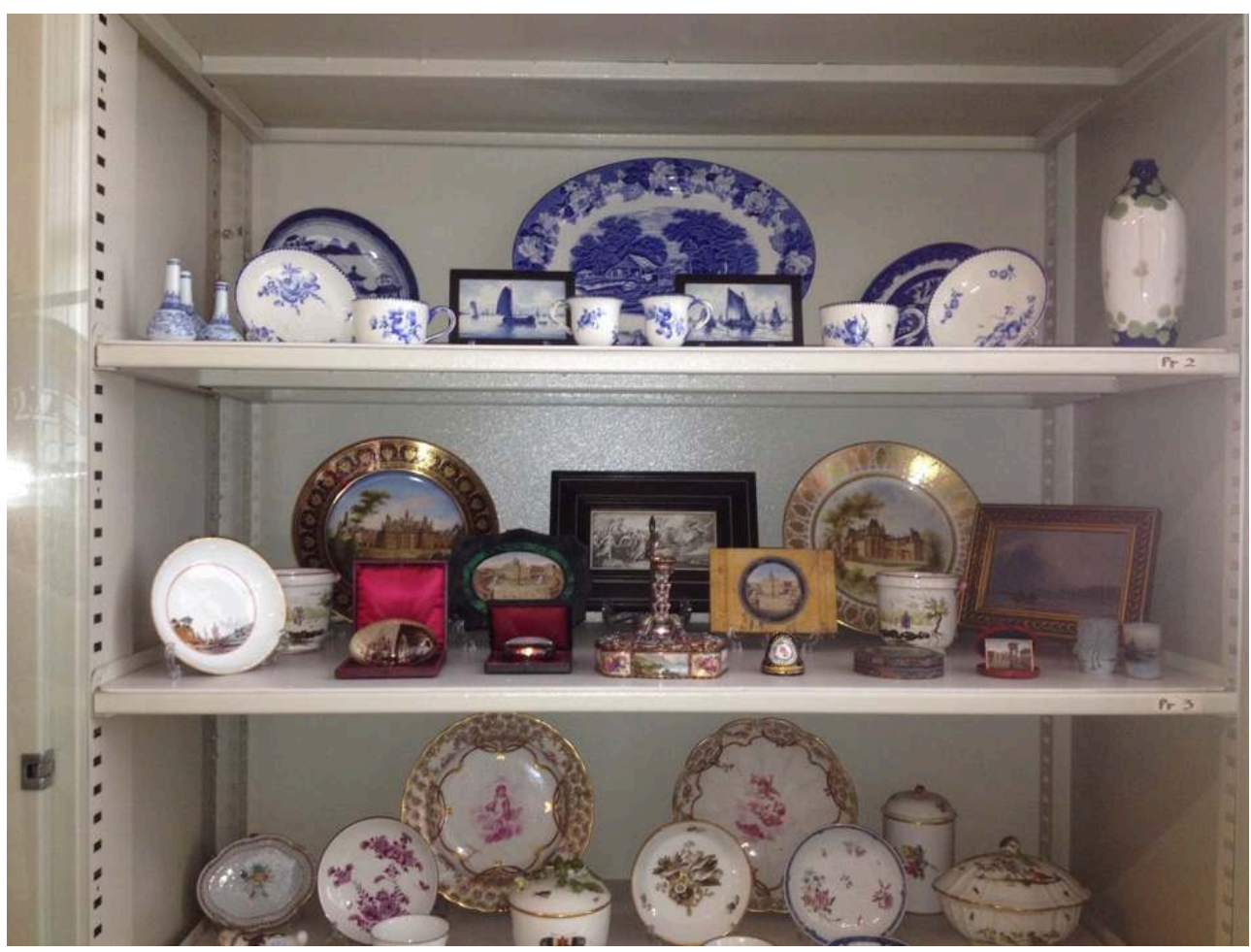

Fig. 5b - Objetos da coleção Ferreira das Neves, Museu D. João VI-Escola de Belas ArtesUniversidade Federal do Rio de Janeiro, 2016

Fotografia da autora 

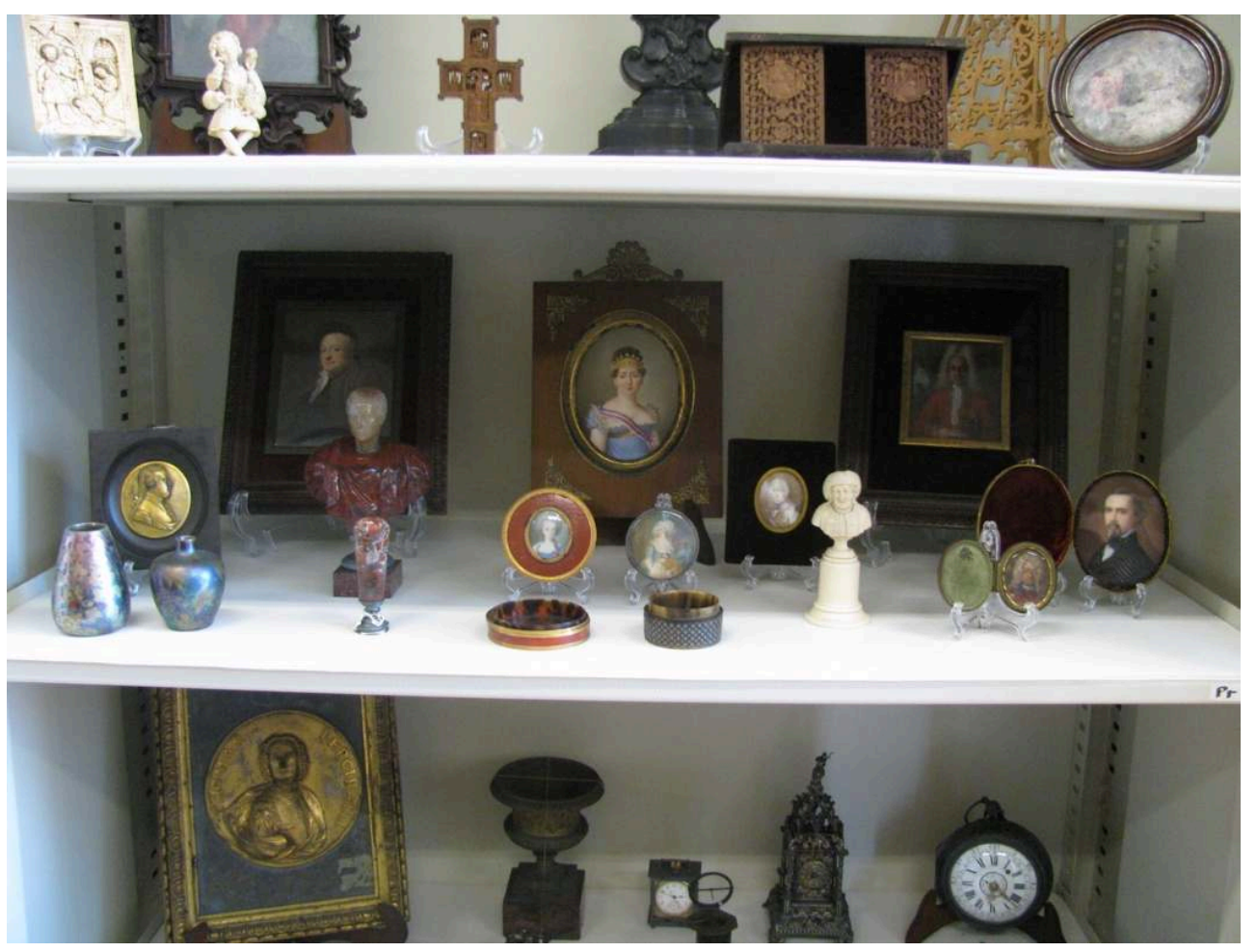

Fig. 5c - Objetos da coleção Ferreira das Neves, Museu D. João VI-Escola de Belas ArtesUniversidade Federal do Rio de Janeiro, 2016

Fotografia da autora

Diante de miniconjuntos, também se incluem peças únicas, nomeadamente a Madona e o menino em relevo de mármore, um par de candelabros em madeira e bronze do Império francês, uma caixa de rapé, um lava-olho em vidro azul, o bom pastor indoportuguês, o peso de papel com caixa de música, ou o porta-selo em metal esmaltado chinês. A coleção inclui, assim, coisas triviais, peças únicas, objetos delicadamente trabalhados, utensílios curiosos, peças excecionais, todos em convivência, numa típica postura eclética de finais do século XIX, celebrando a estética da acumulação.

Originalmente, a coleção era maior e ficou parte guardada dentro de caixotes em Lisboa e Paris até à morte de Jerônimo Ferreira das Neves no ano de 1918, ocorrida em Niterói, capital do estado do Rio de Janeiro. Por meio de um processo de disputa entre herdeiros, que ocorreu em 1919 e 1921 na 2. ${ }^{a}$ vara cível do Tribunal Judicial da Comarca de Lisboa, todos os bens existentes na Europa foram arrolados e pode-se medir as escolhas de Eugênia das Neves para configurar a coleção. E Eugênia Neves não se privou de se colocar por meio de leques, joias, frascos de perfume, colchas, apliques de missangas ou cabos de sombrinhas. Segundo depoimento de Eugênia das Neves no processo, os objetos estavam guardados em caixas há cerca de 20 anos, o que coincide com o anúncio da Gazeta de Notícias (8 out. 1901) sobre a chegada do casal ao Brasil em outubro de 1901 no paquete francês Cordillière. Os motivos que levaram o casal a voltar para o Brasil sem os seus preciosos bens, mantendo-os à distância por tantos anos, ainda estão por desvendar. Porém, se os mantiveram guardados, é possível que tivessem a intenção de recuperá-los um dia, seja retornando a Portugal ou remetendoos para o Brasil.

30 Em Lisboa, o casal Ferreira das Neves morou na rua das Flores, em frente ao palácio Quintela, lugar de efervescências e onde se concentrava a intelectualidade lisboeta, 
lugar privilegiado onde Jerônimo Ferreira das Neves poderia receber os amigos para compartilhar os seus livros raros e a sua coleção. Contudo, não foi encontrada documentação que comprovasse a propriedade do imóvel, nem tampouco este é mencionado no inventário, o que permite supor que o casal o alugasse.

Em Portugal, Jerônimo Ferreira das Neves era conhecido especialmente como bibliófilo, levando a conjeturar que tal identidade poderia ter encoberto a visibilidade das outras peças da sua coleção, as peças artísticas, um fenómeno que pode ter também um viés historiográfico. Normalmente, os estudos sobre itens da coleção tenderam a enfoques especializados, detendo-se em livros ou medalhas ou gravuras ou porcelanas ou pinturas ou relevos. É como se a tendência e a demanda por especialização das coleções, que se fortaleceram no século XX, estivessem a par e passo com as especializações dos museus ou do que mostravam - ciência ou história ou arte -, dos estudos museológicos e de história da arte e, nesse sentido, dificultassem o interesse do estudo por um conjunto enciclopédico que desse conta de livros $\underline{\mathrm{e}}$ medalhas $\underline{\mathrm{e}}$ gravuras e porcelanas $\underline{\mathrm{e}}$ pinturas e relevos. Outra possibilidade é presumir que as peças artísticas tenham sido adquiridas por Eugênia Neves, ela também colecionadora, talvez mais afeita a porcelanas, quadros, têxteis e objetos religiosos, enquanto o marido canalizasse o seu interesse por livros, moedas, medalhas, relógios e armas.

\section{Conclusão}

Diante da multiplicidade de objetos constantes nos acervos nacionais mencionados e especialmente da coleção Ferreira das Neves, conjugando ciência, história e arte, o mais importante não é somente compreender essa diversidade, mas como esta foi tratada por diferentes gerações que priorizaram certos recortes, dotando cada museu de um perfil reconhecido pelo público, com modalidades de conhecimento apartadas, e perceber como na contemporaneidade ainda validam (ou não) seu ecletismo. Talvez tenhamos de voltar a entender essas caixas de tesouros imbuídos da mesma curiosidade que fez com que os colecionadores oitocentistas reunissem tanta diversidade para compreender o mundo - diante da sua totalidade e na sua dimensão humana que, como tal, traz na própria constituição a indivisível ligação entre ciência, história e arte.

\section{BIBLIOGRAFIA}

“Testamento de Eugênia Barbosa de Carvalho Neves - 27/7/1934." In Autos de Inventário dos Bens Deixados pela Finada. Rio de Janeiro: 11/06/1947.

Abreu, Regina. 1996. A Fabricação do Imortal: Memória, História e Estratégias de Consagração no Brasil. Rio de Janeiro: Rocco.

Baldasarre, María Isabel. 2006. Los Dueños del Arte: Coleccionismo y Consumo Cultural en Buenos Aires. Buenos Aires: Edhasa. 
Christo, Maraliz de C. V. 2016. "Doações da Viscondessa de Cavalcanti à Escola Nacional de Belas Artes." In Coleções de Arte em Portugal e Brasil nos Séculos XIX e XX. As Academias de Belas Artes do Rio de Janeiro, Lisboa, Porto, 1816-1836. Ensino, Artistas, Mecenas e Coleções, ed. Maria João Neto e Marize Malta, 513-523. Casal de Cambra: Caleidoscópio.

Dilworth, Leah, ed. 2003. Acts of Possession. Collecting in America. New Brunswick, New Jersey, London: Rutgers University Press.

Gazeta de Notícias. 1901. Rio de Janeiro, n.ำ 288, 8 de outubro de 1901.

Georgel, Chantal. 2015. "O Colecionador e o Museu: ou como Mudar a História da Arte?" Museologia e Interdisciplinaridade, vol. III, n. 6 (mar./abr.): 277-286.

Guimarães, Manoel Luiz Salgado. 2006. "O Culto da Saudade: Fazendo História com o Coração. In Culto da Saudade na Casa do Brasil. Gustavo Barroso e o Museu Histórico Nacional (1922-1959), Aline Montenegro Magalhães, 7-12. Fortaleza: Museu do Ceará, Secretaria da Cultura do Estado do Ceará.

Hall, Stuart. 1997. A Identidade Cultural na Pós-modernidade. Rio de Janeiro: DP \& A.

IHGB. Instituto Histórico e Geográfico do Brasil (IHGB). 2018. Consultado em maio, 2018. https:// www.ihgb.org.br/ihgb/historico.html

Knauss, Paulo, e Moema Alves. 2015. "Guilherme Guinle: Arte e Colecionismo no Brasil na Primeira Metade do Século XX.” In Coleções de Arte: Formação, Exibição, Ensino, org. Ana Cavalcanti et al., 223-232. Rio de Janeiro: Rio Book's, Faperj.

Knauss, Paulo. 2001. “O Cavalete e a Paleta: A Arte de Colecionar no Brasil.” In Anais do Museu Histórico Nacional, vol. 33, 23-44.

León, Aurora. 2010. El Museo. Teoría, Práxis y Utopia. Madrid: Cátedra.

Lopes, Maria Margaret. 1997. O Brasil Descobre a Pesquisa Científica. São Paulo: Hucitec.

Magalhães, Aline Montenegro. 2006. Culto da Saudade na Casa do Brasil. Gustavo Barroso e o Museu Histórico Nacional (1922-1959). Fortaleza: Museu do Ceará, Secretaria da Cultura do Estado do Ceará.

Malta, Marize. 2012. "Sobre Sentidos dos Objetos Conforme Lugares que Ocupam: Um Olhar sobre a Coleção Ferreira das Neves." In Instituições da Arte, ed. Emerson Dionisio de Oliveira e Maria de Fátima Morethy Couto, 191-207. Porto Alegre: Zouk.

Malta, Marize. 2016. "Extraordinária Desconhecida: A Coleção de Eugênia e Jerônimo Ferreira das Neves." In Histórias da Arte em Coleções. Modos de Ver e Exibir em Brasil e Portugal, org. Marize Malta et al., 107-123. Rio de Janeiro: Rio Book's, Faperj.

Malta, Marize. 2017. "Entre Perdas e Danos: Separação do Acervo da Escola Nacional de Belas Artes e a Constituição do Museu Nacional de Belas Artes.” In Histórias da Escola de Belas Artes: Revisão Crítica de sua Trajetória, org. Ana Cavalcanti et al., 142-160. Rio de Janeiro: Nau Editora. Museu Histórico Nacional. 2018. Consultado em maio, 2018. http://mhn.museus.gov.br/ index.php/o-museu/ /

Museu Nacional - UFRJ. 2018. Consultado em maio, 2018. http://www.museunacional.ufrj.br/dir/ omuseu/omuseu.html

Pellegrini, Emanuele. 2018. “Le Intermittenze del Gusto.” In Voglia d'Italia. Il Collezionismo Internazionale nella Roma del Vottoriano, 13-47. Roma: Polo Museale del Lazio, Arte'm. 
Pereira, Sonia Gomes. 2009. “Coleção Jerônimo Ferreira das Neves: Uma Coleção Portuguesa no Museu D. João VI.” In Actas do III Seminário Internacional Luso-Brasileiro, 245-259. Porto: CEPESE, Universidade do Porto.

Pereira, Sonia Gomes. 2016. “As Coleções Lebreton e D. João VI e o Início do Colecionismo da Academia de Belas Artes do Rio de Janeiro." In Histórias da Arte em Coleções. Modos de Ver e Exibir em Brasil e Portugal, org. Marize Malta et al., 35-48. Rio de Janeiro: Rio Book's, Faperj.

Ricoeur, Paul. 2000. La Mémoire, l'Histoire, l'Oubli. Paris: Éditions du Seuil.

Santos, Francisco Marques dos. 1940. “O Leilão do Paço Imperial.” In Anuário do Museu Imperial, vol.1, 151-316. Petrópolis: Museu Imperial.

Santos, Myrian Sepúlveda dos. 2006. A Escrita do Passado em Museus Históricos. Rio de Janeiro: Garamond, MinC, IPHAN, DEMU.

Serrão, Vítor. 1999. "Quatro Ignorados Painéis dos Mestres de Ferreirim no Museu D. João VI da Universidade Federal do Rio de Janeiro." In Actas do Seminário Internacional Estudo da Pintura Portuguesa, 123-127. Lisboa: Instituto José de Figueiredo.

Silva, Raquel Henriques da. 2003. "O Coleccionismo de Artes no Portugal dos Oitocentos." In Henri Burnay: De Banqueiro a Coleccionador, coord. Maria Antónia Pinto de Matos, 11-21. Lisboa: CasaMuseu Dr. Anastácio Gonçalves.

Socias, Immaculada, e Dimitra Glozgkou. 2013. Nuevas Contribuciones en Torno al Mundo del Colecionismo de Arte Hispánico en los Siglos XIX y XX. Gijón: Ediciones Trea.

Sousa Viterbo, Francisco Marques de. 1903. Noticia de Alguns Pintores Portuguezes e de Outros que, sendo Estrangeiros, Exerceram a sua Arte em Portugal. Lisboa: Typographia da Academia Real das Sciencias.

Sousa Viterbo, Francisco Marques de. 1915. Artes e Indústrias Metálicas em Portugal. Relojoaria, Sinos e Sineiros. Coimbra: Imprensa da Universidade.

Teixeira Leite, José Roberto. 1960. "Pinturas Flamengas ou de Estilo Flamengo dos Séculos XV e XVI no Brasil.” Revista Módulo, n. 20: 24-29.

Telles, Patricia D. 2017. o Cavaleiro Brito e o Conde da Barca: Dois Diplomatas Portugueses e a Missão Francesa de 1816 no Brasil. Lisboa: Documenta.

Tribunal Judicial da Comarca de Lisboa. $2^{\text {a }}$ Vara. $2^{\circ}$ Ofício. 1919. Autos cíveis de inventário entre maiores. Inventariado: Dr. Jerônimo Ferreira das Neves. Inventariante: D. Maria Ferreira das Neves. Processo n.․ 2004.

Vasconcelos, Joaquim de. 1896. Quatro Diálogos da Pintura Antigua: Francisco de Hollanda, Miguel Angelo, Vittoria Colonna, Lattanzio Tolomei. Porto: [s.n.].

Viana, Luis Diaz. 2008. "Museus, Histórias, Memórias e Nação: A Representação do Espaço e do Tempo em um Cenário de Poder." In A Democratização da Memória: A Função Social dos Museus Iberoamericanos, org. Mario Chagas et al., 15-26. Rio de Janeiro: Museu Histórico Nacional.

Viana, Marcele L. 2017. "Regimento de 1948, os Novos Cursos e o Curso de Arte Decorativa." In Histórias da Escola de Belas Artes: Revisão Crítica de sua Trajetória, org. Ana Cavalcanti et al., 89-96. Rio de Janeiro: Nau Editora. 


\section{RESUMOS}

Jerônimo Ferreira das Neves (1854-1918), um colecionador brasileiro, viveu, com a sua esposa Eugênia Barbosa de Carvalho Neves (1860-1946), em Lisboa nas décadas de 1880 e 1890, reunindo uma coleção eclética, composta por livros raros, moedas, medalhas e objetos de arte. 0 casal não juntou apenas peças antigas de elevado valor estético, mas também objetos do quotidiano de uso comum, perfazendo uma diversidade complexa, reflexo das práticas colecionistas do período e dos chamados museus ecléticos. Parte da coleção foi doada à Escola Nacional de Belas Artes do Rio de Janeiro, antiga Academia Imperial, em 1947, por vontade testamentária de Eugênia Neves, integrando o acervo do Museu D. João VI, museu da referida Escola, criado em 1979. Quase 60 anos depois da doação de Eugênia Neves, após o Museu D. João VI ter sido alvo de renovação museológica na primeira década do século XXI, foi possível expor a coleção em toda a sua diversidade, entre outras obras de ensino académico. Esta apresentação da coleção recupera a sua natureza eclética e instiga novos questionamentos sobre as coleções oitocentistas, modos de exibição e de compreensão da arte e das suas práticas historiográficas. Pretendemos, assim, a partir das reflexões sobre museus nacionais brasileiros e as experiências de colecionismo de Oitocentos no Rio de Janeiro, discutir as repercussões das doações a instituições públicas, dos seus usos e implicações na contemporaneidade.

Jerônimo Ferreira das Neves (1854-1918), a Brazilian art collector, lived with his wife Eugênia Barbosa de Carvalho Neves (1860-1946) in Lisbon in the 1880s and 1890s, collecting an eclectic collection of rare books, coins, medals and art objects. The couple not only collected old pieces of aesthetic value, but also objects of life, of common use, making a complex diversity, reflecting the collecting practices of the period and of the so-called eclectic museums. Part of the collection was donated to the Escola Nacional de Belas Artes of Rio de Janeiro, formerly the Academia Imperial, in 1947, by testamentary will of Eugênia Neves, joining the collections of the D. João VI Museum, a museum of the Escola Nacional de Belas Artes, created in 1979. Nearly 60 years after the donation of Eugênia Neves, following the renovation of the D. João VI Museum in the first decade of $21^{\text {st }}$ century, the collection was publicly available in all its diversity and among the works of academic teaching. Such presentation of the collection recovers its eclectic nature and instigates new questions about nineteenth-century collections, modes of exhibition and understandings of art and its historiographic practices. Thus, from the reflections on Brazilian national museums and the collecting experiences of the $19^{\text {th }}$ century in Rio de Janeiro, we discuss the repercussions of the donations to public institutions, their uses and implications in contemporary times.

\section{ÍNDICE}

Keywords: Private colleting, eclectic museum, Jerônimo Ferreira das Neves, collection Ferreira das Neves, Museum D. João VI

Palavras-chave: Colecionismo privado, museu eclético, Jerônimo Ferreira das Neves, coleção Ferreira das Neves, Museu D. João VI

\section{AUTOR}

\section{MARIZE MALTA}

Professora associada da Escola de Belas Artes da Universidade Federal do Rio de Janeiro, atuando na graduação e pós-graduação em Artes Visuais. O seu domínio de investigação é em história e teoria da arte/artes decorativas, artefactos e ambientes oitocentistas, arte doméstica, objetos 
malditos, condição decorativa e/ou artística e da sua relação com imagem e lugar, tendo como foco as coleções e os modos de exibição. É líder dos grupos de pesquisa "Entresséculos Mudanças e Continuidades nas Artes no Brasil nos Séculos XIX e XX" e "MODOS - História da Arte: Modos de Ver, Exibir e Compreender”. Realizou, entre 2017 e 2018, estágio pós-doutoral no Instituto de História da Arte da Universidade de Lisboa, com bolsa da CAPES (Coordenação de Aperfeiçoamento de Pessoal de Nível Superior).

Escola de Belas Artes da Universidade Federal do Rio de Janeiro, Rua Maurício Joppert da Silva, s/ n, Cidade Universitária, Ilha do Fundão, Rio de Janeiro, Brasil, marizemalta@eba.ufrj.br 